\title{
Hexakis(PCP-Platinum and -Ruthenium) Complexes by the Transcyclometalation Reaction and Their Use in Catalysis
}

\author{
Harm P. Dijkstra, Martin Albrecht, Serenella Medici, Gerard P. M. van Klink, \\ Gerard van Koten*
}

Debye Institute, Department of Metal-Mediated Synthesis, Utrecht University, Padualaan 8, 3584 CH Utrecht, The Netherlands

Phone: + (31)-30-253-3120. Fax: (+31)-30-252-3615, e-mail: g.vankoten@chem.uu.nl

Received: June 13, 2002; Accepted: September 1, 2002

Abstract: Hexakis(PCP-pincer) complexes $\left[\mathrm{C}_{6}(\mathrm{PtBr}\right.$ $\left.(\mathrm{PCP})\}_{6}\right](\mathbf{5 d})$ and $\left[\mathrm{C}_{6}\left\{\mathrm{RuCl}(\mathrm{PCP})\left(\mathrm{PPh}_{3}\right)\right\}_{6}\right](\mathbf{5 e})$ were synthesized via the transcyclometalation (TCM) procedure. Mixing the hexakis(PCHP-arene) ligand 7 with six equivalents of $[\mathrm{PtBr}(\mathrm{NCN})]$ (1a) or $\left[\mathrm{RuCl}(\mathrm{NCN})\left(\mathrm{PPh}_{3}\right)\right](\mathbf{1 b})$, respectively, resulted in the selective metalation of all PCP-ligand sites and the concomitant formation of six equivalents of the $\mathrm{NCHN}$-arene ligand. This procedure was found to be superior over existing metalation procedures. In addition, hexakisruthenium complex 5e was applied as homogeneous catalyst in the hydrogen transfer reactions of cyclohexanone, acetophenone and benzophenone to the corresponding alcohols. In these reactions, the activity per ruthenium center of $\mathbf{5 e}$ was found to be of the same order of magnitude as that of the mononuclear analogue $\left[\mathrm{RuCl}(\mathrm{PCP})\left(\mathrm{PPh}_{3}\right)\right] \mathbf{3 b}$, indicating that all ruthenium centers act as independent catalytic sites.

Keywords: homogeneous catalysis; multimetallic complexes; platinum; P ligands; transcyclometalation; ruthenium

\section{Introduction}

In the last decade, organometallic complexes containing the monoanionic, terdentate coordinating PCP-pincer ligand $\left(\mathrm{PCP}=\left[\mathrm{C}_{6} \mathrm{H}_{3}\left(\mathrm{CH}_{2} \mathrm{PR}_{2}\right)_{2}-2,6\right]^{-}\right)$have been intensively studied as homogeneous catalysts in organic transformations, e.g., aldol reactions, ${ }^{[1]}$ asymmetric allylic alkylations, ${ }^{\left[{ }^{2}\right]}$ dehydrogenation of alkanes, ${ }^{\left[{ }^{3]}\right.}$ Heck reactions ${ }^{[4]}$ and hydrogen transfer reactions. ${ }^{[5]}$ The preparation of these PCP-metal complexes often proceeds by $\mathrm{C}-\mathrm{H}$ bond activation using suitable transition metal precursors. ${ }^{[6]}$ Recently, we reported the synthesis of ruthenated and platinated PCP-ligands applying the transcyclometalation (TCM) procedure (Scheme 1). ${ }^{[7]}$ In close relation to (organic) transesterification reactions, TCM reactions comprise the substitution of one cyclometalated ligand by another. For example, the reaction of $[\mathrm{M}(\mathrm{NCN})] \mathbf{1}$ with PCHP 2 affords quantitatively complex $[\mathrm{M}(\mathrm{PCP})] \mathbf{3}$ and the free arene $\mathrm{NCHN} 4$ for both $\mathrm{ML}=\mathrm{PtBr}(\mathbf{1 a})$ or $\mathrm{RuCl}\left(\mathrm{PPh}_{3}\right)$ (1b) (Scheme 1). A crucial aspect of the TCM reactions is the difference in bond strengths of the various metalheteroatom bonds, which have to be stronger in the products than in the starting material (viz. M-P stronger than $\mathrm{M}-\mathrm{N}$ bond). The reaction pathway followed is similar to that of the electrophilic aromatic substitution reaction. ${ }^{[\mathrm{bb}]}$ In addition, the reactions take place under mild conditions (in terms of temperature, pressure and reagents), are very selective for ortho, ortho-metalation and proceed in quantitative yields with the NCHN-arene ligand as the only coproduct.

Recently, we started to develop shape-persistent nanosize multi(pincer-metal) complexes and to explore their application in a nanofiltration membrane reactor. ${ }^{[8]}$ Due to their shape-persistence, these soluble complexes were found to be retained very efficiently by nanofiltration membranes, ${ }^{[8 c]}$ allowing their use as homogeneous catalysts in organic transformations under continuously operating reaction conditions. ${ }^{[8 \mathrm{~d}, 9]}$

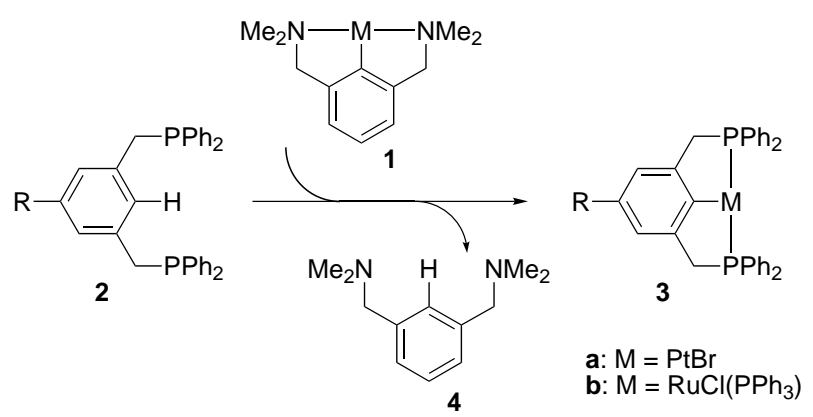

Scheme 1. Synthesis of PCP-ruthenium and -platinum complexes using the TCM procedure. 


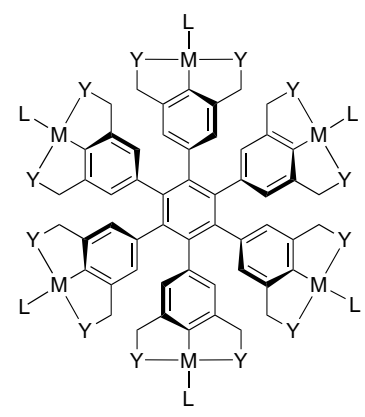

$$
\begin{aligned}
& \text { 5a: } M=P d, Y=S P h \\
& \text { 5b: } M=P d, Y=P P h_{2} \\
& \text { 5c: } M=P d, Y=p^{2}=P_{r a z o l}-1-y l \\
& \text { 5d: } M=P t, Y=P P h_{2}
\end{aligned}
$$

Figure 1. Shape-persistent multi(YCY-pincer-metal) complexes.

In addition, highly symmetric tris- and hexakismetallic complexes of type $\mathbf{5}$ and $\mathbf{6}$ (Figure 1) were used as templates in the synthesis of large heterocycles (ring size: $69-75$ atoms) using olefin metathesis for the ring closing reaction. ${ }^{[10]}$ Until now, however, mainly palladium and in some cases platinum (only in combination with NCN-type ligands) complexes were used for these purposes. ${ }^{[8,10]}$ For a broad application of these multimetallic complexes in the field of homogeneous catalysis and template-directed synthesis, it is desirable to synthesize such systems containing different metals. Since monometallic PCP-complexes can be applied in a broader and complementary range of organic transformations, gaining access to shape-persistent nanosize multi(PCP-metal) complexes containing various metals also would allow the application of these catalytic reactions under continuously operating conditions in a nanofiltration membrane reactor.

Recently, the synthesis of hexakis(PCP-platinum and -ruthenium) complexes $\left[\mathrm{Y}=\mathrm{PPh}_{2}, \mathrm{ML}=\mathrm{PtBr}(\mathbf{5 d})\right.$ or $\mathrm{RuCl}\left(\mathrm{PPh}_{3}\right)(\mathbf{5 e})$, Figure 1] using the TCM reaction was communicated. ${ }^{[11]}$ Here, a full account of these data is given. In addition, the application of the hexakis(PCP$\mathrm{Ru}$ )-complex 5e as a homogeneous catalyst in hydrogen transfer reactions of various ketones will be discussed.

\section{Results and Discussion}

Recently, we reported the synthesis of the hexakis(PCHP-arene) ligand 7 (Figure 2) and its palladation procedure. ${ }^{[8 b]}$ However, various attempts to directly cycloplatinate ligand $\mathbf{7}$ six times failed in spite of using different metal precursors that previously were successfully applied for the cycloplatination of analogous single site PCP ligands. ${ }^{[12]}$ Treatment of $\mathbf{7}$ with six equivalents of $\left[\mathrm{PtCl}_{2}(\mathrm{cod})\right]$ in mesitylene at reflux conditions, resulted in the formation of intractable mixtures. Reaction of six equivalents of $c i s$ - $\left[\mathrm{PtCl}_{2}\left(\mathrm{PPh}_{3}\right)_{2}\right]$ with 7

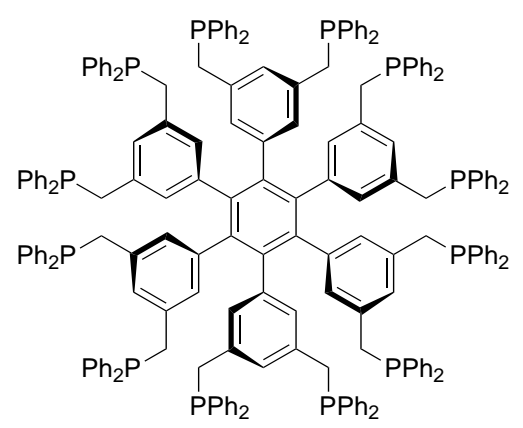

7

Figure 2. Hexakis(PCP) ligand 7.

in $\mathrm{CH}_{2} \mathrm{Cl}_{2}$ at room temperature also failed. Most likely, the local phosphine concentration, which is exceptionally high in 7 , leads to the formation of $\eta^{2}-P, P^{\prime}$ coordinated platinum centers which do not undergo subsequent $\mathrm{C}-\mathrm{H}$ bond activation. This activation process is anticipated to require transient decoordination of one phosphine ligand in order to generate the electronically and coordinatively unsaturated reactive intermediate. ${ }^{[13]}$ An alternative method is to introduce six platinum centers via a multiple lithiation/transmetalation procedure, a method developed to metalate NCN-pincer ligands. ${ }^{[14]}$ Only one example is known in which a PCP ligand is used in a transmetalation procedure. ${ }^{[15]}$ Various attempts, however, to lithiate 7 with six equivalents of $n$-BuLi or tert-BuLi in hexanes at various temperatures, followed by a transplatination with $\left[\mathrm{PtCl}_{2}(\mathrm{cod})\right]$ or $\left[\mathrm{PtCl}_{2}\left(\mathrm{SEt}_{2}\right)_{2}\right]$ failed. Probably, bis(ortho)-lithiation of $\mathbf{7}$ suffered from low selectivity because of the relatively high acidity of the neighboring benzylic protons. Thus, both direct cyclometalation and lithiation/transmetalation did not lead to full and selective platination of $\mathbf{7}$.

As reported earlier, in the TCM reaction the precursor $[\mathrm{PtBr}(\mathrm{NCN})]$ (1a, Scheme 1) has (thermodynamically and kinetically) a rigid trans- $N, N$-configuration and, therefore, forces eventually formed bisaryl platinum intermediates, i.e., $[\mathrm{Pt}(\mathrm{PCP})(\mathrm{NCN})]$ type structures (Figure 3 ), in a trans-C,C-configuration. ${ }^{[76]}$ Most of the metal precursors used in cyclometalation reactions, however, do not ultimately exclude the

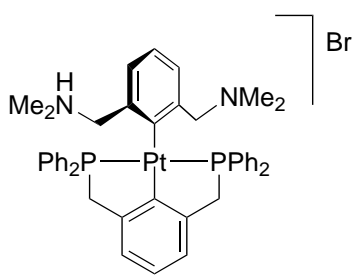

Figure 3. trans- $C, C$-Bisarylplatinum intermediate in the TCM reaction. ${ }^{[7 \mathrm{~b}]}$ 
formation of alternative species with the heteroatom donors in a mutual cis-configuration. This prevents cyclometalation and is likely to promote rigid $\eta^{2}-P, P^{\prime}$ bidentate cis-coordination of adjacent phosphine sites. ${ }^{[16]}$ Particularly with multisite ligands such as 7, possessing a high concentration of coordination sites at the periphery, this is likely to take place. Since the TCM reaction proceeds via a trans-configuration, competitive undesired coordination modes are prevented, making the TCM reaction very promising for metalating ligands such as 7. In addition, the TCM reaction proceeds in quantitative yield, which is a crucial aspect when applying such a metalation procedure for preparing multimetallic complexes.

Treatment of hexakis(PCHP-arene) ligand 7 with six equivalents of $[\mathrm{PtBr}(\mathrm{NCN})](\mathbf{1 a})$, led to the formation of hexakis(PCP-Pt-Br) 5d in $70 \%$ isolated yield (Scheme 2) (equal to a 94\% yield per single ligand site). Separation of $\mathbf{5 d}$ from NCHN, the only other formed product, was achieved by a double extraction and precipitation procedure using $\mathrm{CH}_{2} \mathrm{Cl}_{2}$ and pentane, respectively. Complete transcyclometalation was unequivocally assessed by multinuclear NMR spectrosco-

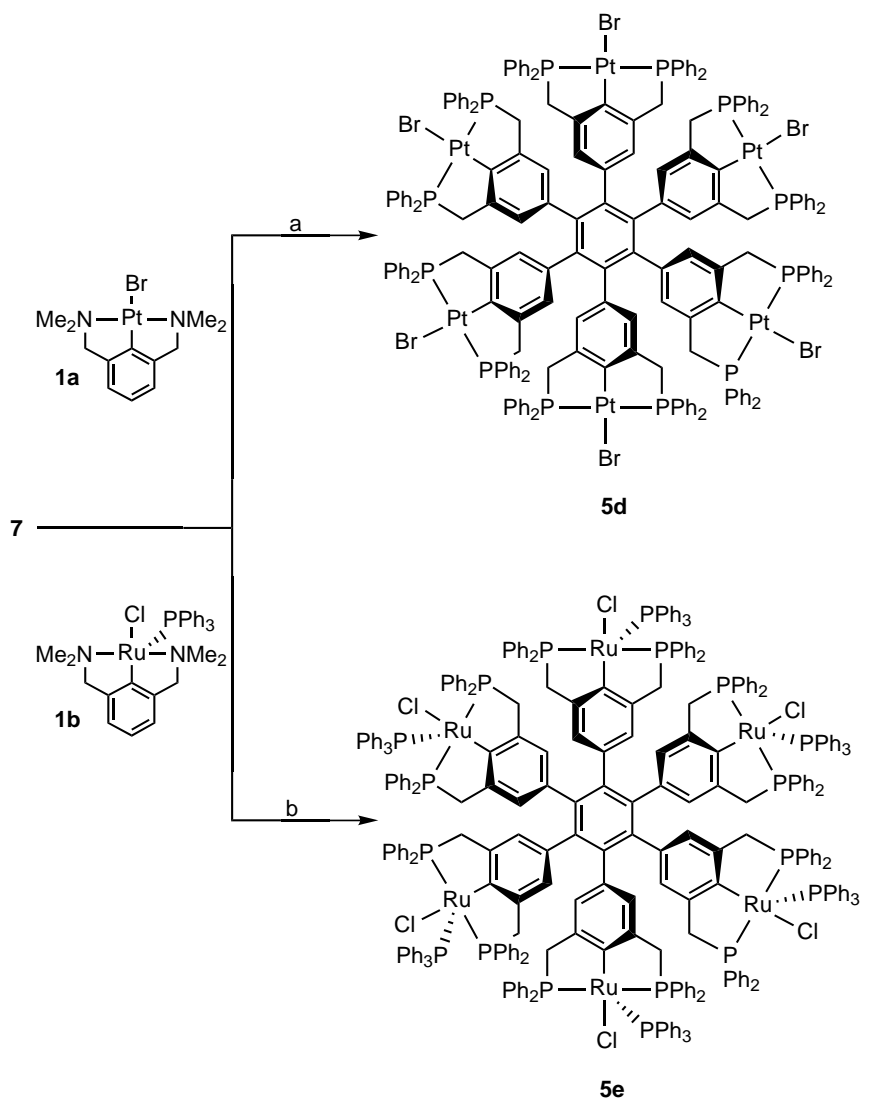

Scheme 2. Synthesis of hexakis(PCP-platinum and -ruthenium) complexes applying the TCM reaction: a) Six equiv. of 1a, toluene, reflux, $3 \mathrm{~d},-6 \mathrm{HCNH}$. b) Six equiv. of $\mathbf{1 b}$, benzene, reflux, $20 \mathrm{~h},-6 \mathrm{HCNH}$. py, elemental analysis and by MALDI-TOF mass spectrometry $\left[\mathrm{m} / \mathrm{z} 4557.74\left(\mathrm{M}^{+}\right)\right.$; calcd. 4557.11]. In the ${ }^{1} \mathrm{H}$ NMR spectrum, the resonances due to the benzylic protons of $\mathbf{5 d}$ are characteristically shifted toward lower field upon metal insertion $\left(\delta_{\mathrm{H}}=2.88\right.$ in 7 and 3.07 in 5d). No signals due to traces of metal-free PCHP units or residual $[\mathrm{PtBr}(\mathrm{NCN})]$ (1a) were detected. The ${ }^{31} \mathrm{P}$ NMR spectrum displays a diagnostic single resonance at 36.1 ppm $\left({ }^{1} J_{\mathrm{Pt}, \mathrm{P}}=2864 \mathrm{~Hz}\right)^{[7 \mathrm{~b}]}$ due to the trans-phosphorus nuclei of the PCP ligand sites that are coordinated to platinum. No signals were observed which could point to only partial metalation, which is remarkable and emphasizes once again the scope of the TCM reaction.

The same procedure is followed to prepare hexakis(PCP-Ru) complex 5e (Scheme 2). Treatment of 7 with six equivalents of $\left[\mathrm{RuCl}(\mathrm{NCN})\left(\mathrm{PPh}_{3}\right)\right](\mathbf{1 b})$, resulted in the formation of the dark green, air-sensitive hexakisruthenium complex 5e in $79 \%$ yield (equal to a 96\% yield per single ligand site). The NMR spectra of this multimetallic species are uniformly broad, which most likely is due to dynamic processes involving a change in mutual orientation of the PCP aryl planes (note that each ruthenium center has a square-pyramidal configuration); Scheme 2 shows only one of the several possible conformations of 5e. The ${ }^{31} \mathrm{P}$ NMR spectrum $\left(\mathrm{CD}_{2} \mathrm{Cl}_{2}\right)$ of $\mathbf{5 e}$ shows two peaks $\left[\delta_{\mathrm{P}} 80.8(\mathrm{~m})\right.$ and $40.7(\mathrm{~m})$, the multiplicity of the peaks is due to different conformers of $\mathbf{5 e}$ ]. These chemical shift values are in agreement with those found for the monometallic analogue $\left[\mathrm{RuCl}(\mathrm{PCP})\left(\mathrm{PPh}_{3}\right)\right] \mathbf{3 b}\left[\delta_{\mathrm{P}} 81.3(\mathrm{t})\right.$ and 36.5 (d)]. Due to the extreme air sensitivity, a correct elemental analysis pointing to the isolation of pure $\mathbf{5 e}$ could not be obtained. Therefore for further analysis, $\mathbf{5 e}$ was converted into [hexakis(PCP-Ru-terpy)] $(\mathrm{X})_{6}$ complex 8a $(\mathrm{X}=\mathrm{Cl})$ containing cationic hexacoordinate ruthenium centers (Scheme 3 ). This was achieved by prolonged reaction $(2 \mathrm{~d})$ of a solution of $5 \mathbf{e}$ with six equivalents of $2,2^{\prime}: 6^{\prime}, 2^{\prime \prime}$-terpyridine (terpy) in methanol at reflux conditions. ${ }^{[6 e]}$ This reaction was accompanied by a characteristic color change from dark green to dark red. The changed geometry around the metal centers in 8a, from distorted square-pyramidal into octahedral, has two advantageous consequences; i) the complex is stable toward air and water, and ii) the coordination geometry around ruthenium has a markedly higher symmetry, thereby reducing the number of potential conformers of 8a. The ${ }^{31} \mathrm{P}$ NMR spectrum now shows a single resonance at $\delta_{P} 41.5$, with a value characteristic for a phosphorus center in a $\left[\mathrm{Ru}(\mathrm{PCP})(\right.$ terpy) $] \mathrm{Cl}$ complex. ${ }^{[6 e]}$ The elemental analysis of $\mathbf{8 a}$ revealed a structure with a molecular formula of $\mathrm{C}_{288} \mathrm{H}_{270} \mathrm{Cl}_{6} \mathrm{~N}_{18} \mathrm{O}_{24} \mathrm{P}_{12} \mathrm{Ru}_{6}$, indicating that for each molecule of $8 \mathbf{a} 24$ water molecules are included. This observation was confirmed by ${ }^{1} \mathrm{H}$ NMR spectroscopy, which showed a large peak at $\delta_{\mathrm{H}} 3.5$, which could not be ascribed solely to small amounts of water present in the deuterated solvents. Replacing the chloride counterions by tetraphenylborate anions, by 


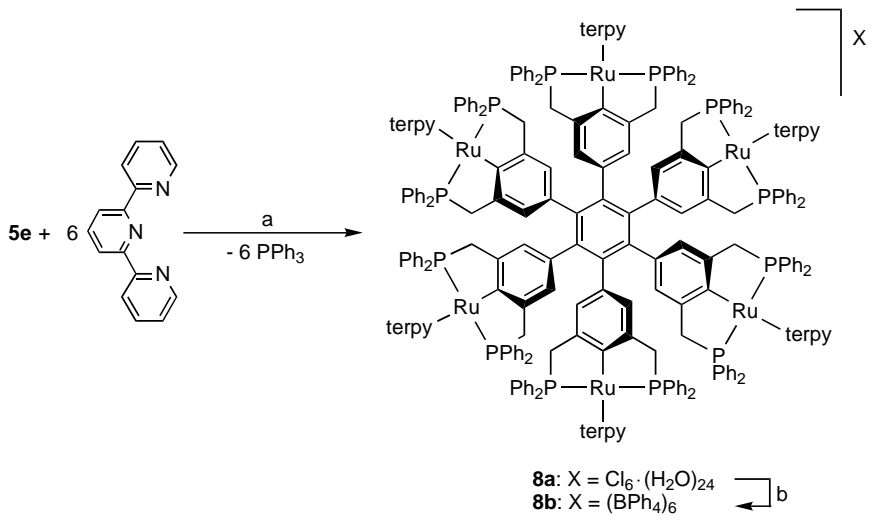

Scheme 3. Synthesis of [hexakis(PCP-Ru-terpy)](X) $)_{6}$ complexes 8a and 8b: a) Six equiv. of $2,2^{\prime}: 6^{\prime}, 2^{\prime \prime}$-terpyridine (terpy), $\mathrm{MeOH}$, reflux, 2 d. b) $\mathrm{NaBPh}_{4}$, acetone, rt, $2 \mathrm{~h}$.

treating 8a with six equivalents of sodium tetraphenylborate in acetone, resulted in the disappearance of the water molecules as was shown by ${ }^{1} \mathrm{H}$ NMR spectroscopy of a solution of $\mathbf{8 b}$ in $\mathrm{CD}_{2} \mathrm{Cl}_{2}$. Interestingly, this observation suggests that the water molecules in 8a have a distinct orientation, e.g., four water molecules could be bound to each chloride anion. Regrettably, no crystals of 8a suitable for X-ray single crystal structure determination could be obtained and thus also the exact binding mode of the co-crystallized water molecules could not be elucidated.

\section{Catalysis}

An important application for multimetallic complexes is their use as homogeneous catalyst in a nanofiltration membrane reactor in order to address the important issue of catalyst recycling. ${ }^{[9]}$ Applying this technique in catalyst recycling results in significantly higher turnover numbers. The presence of toxic metals in the product stream is also prevented. It was already shown that a high degree of shape-persistence in the organic backbone of such materials is important to acquire optimal retentions of these catalysts by nanofiltration membranes. ${ }^{[8 c]}$ So far, we only explored the use of shapepersistent multi(NCN-Pd $\left.{ }^{\mathrm{II}}\right)$ complexes as homogeneous catalysts. ${ }^{[8 \mathrm{~b}, \mathrm{e}]}$ It is known that monometallic PCP- $\mathrm{Ru}^{\mathrm{II}}$ complexes are very active as homogeneous hydrogen transfer catalysts in the conversion of ketones to alcohols. ${ }^{[5]}$ Encouraged by these results, we decided to test hexakis(PCP-Ru $\left.{ }^{\mathrm{II}}\right)$ complex $\mathbf{5 e}$ as a homogeneous catalyst in the hydrogen transfer reaction of several ketones to the corresponding alcohols (Scheme 4). In order to make a direct comparison possible with the monoruthenated species, we also tested $[\mathrm{RuCl}(\mathrm{PCP})$ $\left(\mathrm{PPh}_{3}\right)$ ] 3b (Scheme 4) under the same conditions. Cyclohexanone, acetophenone and benzophenone were selected as reagents. In all reactions, $0.1 \mathrm{~mol} \%$

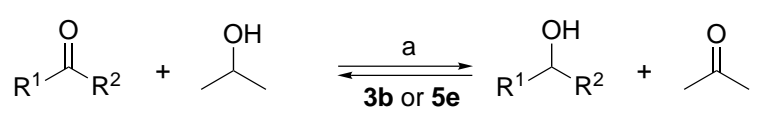

$\mathrm{R}^{1}, \mathrm{R}^{2}=$ alkyl or aryl

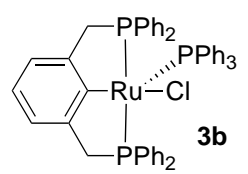

Scheme 4. PCP-Ruthenium complexes $\mathbf{3 b}$ and $\mathbf{5 e}$ as hydrogen transfer catalysts. a) $0.1 \mathrm{~mol} \%[\mathrm{Ru}],[\mathrm{KOH}] /[\mathrm{Ru}]=20$, $20 \mathrm{mmol}$ ketone, $30 \mathrm{~mL} i$-PrOH, reflux.

[Ru], $2 \mathrm{~mol} \%$ potassium hydroxide and $0.67 \mathrm{M}$ ketone in $i$-propanol was used.

The turnover frequencies (TOF) obtained with catalysts $\mathbf{3 b}$ and $\mathbf{5 e}$ in the hydrogen transfer reactions are summarized in Table 1. In the reduction of cyclohexanone to cyclohexanol (entries 1 and 2, Table 1), the catalytic activity of $\mathbf{3 b}$ was found to be twice as high as that of hexametallic catalyst 5e (per ruthenium center). Nevertheless, a TOF of 4300 means complete conversion within 30 minutes under the given reaction conditions. ${ }^{[17]}$ In the hydrogen transfer reaction of acetophenone and benzophenone to 1-phenylethanol (entries 3 and 4) and benzhydrol (entries 5 and 6), respectively, the activity of $\mathbf{5 e}$ (per ruthenium center) was found to be equal to that of the mononuclear analogue 3b (entry 3 vs. 4 and 5 vs. 6). These latter results, clearly indicate that all six ruthenium centers in 5e act simultaneously as independent catalytic sites for this type of reaction.

In the research area of homogeneous catalyst recycling using nanofiltration membranes, not only an efficient retention of the catalyst by the membranes is important, but also efficient use of all catalytic sites and

Table 1. Hydrogen transfer reaction of ketones using $\mathbf{3 b}$ and 5e as catalysts.

\begin{tabular}{|c|c|c|c|c|}
\hline Entry & Substrate & Product & Catalyst & $\mathrm{TOF}\left[\mathrm{h}^{-1}\right]^{[\mathrm{a}]}$ \\
\hline 1 & & & $5 e$ & 4300 \\
\hline 2 & & & $\mathbf{3 b}$ & 9300 \\
\hline 3 & & & $5 e$ & 2200 \\
\hline 4 & & & $\mathbf{3 b}$ & 2300 \\
\hline 5 & & & $5 e$ & 320 \\
\hline 6 & & & $\mathbf{3 b}$ & 350 \\
\hline
\end{tabular}

[a] Turnover frequency (moles of ketone converted to alcohol per mole of $[\mathrm{Ru}]$ per hour), determined in the first $50 \%$ conversion. 
catalyst stability is a prerequisite. To investigate the stability of the catalyst in hydrogen transfer reactions, 5e was tested again in the reduction of cyclohexanone to cyclohexanol using the same reaction conditions as described before. This time, however, after complete conversion, heating of the reaction mixture at reflux conditions was continued for an additional 20 hours. Subsequent addition of cyclohexanone and monitoring the reaction in time, revealed that the catalyst (5e) still possessed the same activity, as a similar TOF was found (TOF = 4000; compare with entry 1 , Table 1$)$. Thus, $5 \mathbf{e}$ shows both an efficient use of all catalytic ruthenium centers and a high catalyst stability in hydrogen transfer reactions, ensuring application of $\mathbf{5 e}$ in hydrogen transfer reactions for prolonged reaction times. Since it was already found that shape-persistent complexes such as $\mathbf{5 e}$ possess high retention rates by nanofiltration membranes, ${ }^{[8]}$ hexanuclear complex $\mathbf{5 e}$ is an attractive candidate as a homogeneous catalyst in a nanofiltration membrane reaction. This research is currently in progress.

Nowadays, an increasing number of macromolecular homogeneous catalysts are reported that show high retentions by nanofiltration membranes and an efficient use of all catalytic sites during catalysis. ${ }^{[9]}$ In future, for nanofiltration membrane technology to be applicable on a large industrial scale, research should be focused on the durability of the catalyst during catalysis. The endurance of many homogeneous catalysts, in contrast to heterogeneous catalysts, do not yet meet the requirements needed for long running continuous catalytic processes. Furthermore, developing recyclable homogeneous catalysts based on a variety of different catalytic units is also desirable, since it allows the application of a broad range of selective organic transformations in a nanofiltration membrane reactor, the first step toward large scale continuous processes.

\section{Experimental Section}

\section{General}

All reactions were carried out using standard Schlenk techniques under an inert nitrogen atmosphere unless stated otherwise. $\mathrm{Et}_{2} \mathrm{O}$, THF and hexanes were carefully dried and distilled from $\mathrm{Na}$ /benzophenone prior to use. $\mathrm{CH}_{2} \mathrm{Cl}_{2}$ was distilled from $\mathrm{CaH}_{2}$. All standard reagents were purchased. Compounds $\mathbf{1 a},{ }^{[8 \mathrm{~b}]} \mathbf{1 b},{ }^{[6]} \mathbf{3} \mathbf{b}^{[18]}$ and $\mathbf{7}^{[8 \mathrm{bb}}$ were prepared according to literature procedures. ${ }^{1} \mathrm{H}$ and ${ }^{13} \mathrm{C}$ NMR spectra were recorded at $25^{\circ} \mathrm{C}$, chemical shifts are in ppm referenced to residual solvent resonances. MALDI-TOF-mass spectra (nitrogen laser emitting at $337 \mathrm{~nm}$ ) were acquired using a Voyager-DE Bio-Spectrometry Workstation mass spectrometer using (3,5-dihydroxybenzoic acid) as the matrix. The samples were dissolved in THF or $\mathrm{CH}_{2} \mathrm{Cl}_{2}(\sim 30 \mathrm{mg} / \mathrm{mL})$ and $0.2 \mu \mathrm{L}$ of both solutions were mixed and placed on a gold MALDI target and analyzed after evaporation of the solvent.
$\mathrm{UV} / \mathrm{Vis}$ spectroscopy was carried out using distilled $\mathrm{CH}_{2} \mathrm{Cl}_{2}$ as solvent and standard quartz cuvettes. Elemental microanalyses were performed by Dornis und Kolbe, Mikroanalytisches Laboratorium, Müllheim a.d. Ruhr, Germany.

\section{Synthesis of 5d}

A solution of hexakis(PCHP) $7(0.20 \mathrm{~g}, 68.7 \mu \mathrm{mol})$ and $[\mathrm{PtBr}(\mathrm{NCN})] \mathbf{1 a}(0.19 \mathrm{~g}, 0.42 \mathrm{mmol})$ in toluene $(50 \mathrm{~mL})$ was heated to reflux for $3 \mathrm{~d}$. The reaction mixture was allowed to cool to room temperature, filtered and the filtrate was evaporated to dryness. The resulting yellow solid was dissolved in $\mathrm{CH}_{2} \mathrm{Cl}_{2}(20 \mathrm{~mL})$ and the product was precipitated from this solution by slow diffusion of pentane. This procedure was repeated twice, affording an off-white solid. Yield: $0.22 \mathrm{~g}$ (70\%). ${ }^{1} \mathrm{H}$ NMR $\left(\mathrm{CDCl}_{3}, 200 \mathrm{MHz}\right): \delta=7.84-6.47(\mathrm{~m}, 132 \mathrm{H}$, $\left.\mathrm{C}_{\text {aryl }}-H\right), 3.07$ (br, $\left.{ }^{3} \mathrm{~J}_{\mathrm{Pt}, \mathrm{H}}=28 \mathrm{~Hz}, 24 \mathrm{H}, \mathrm{ArCH}_{2} \mathrm{P}\right) ;{ }^{13} \mathrm{C} \mathrm{NMR}$ $\left(\mathrm{CDCl}_{3}, 75 \mathrm{MHz}\right): \delta=161-105\left(C_{\text {aryl }}\right), 38.4\left({ }^{3} J_{\mathrm{C} P \mathrm{Pt}}\right.$ not resolved, $\left.\mathrm{CH}_{2} \mathrm{P}\right) ;{ }^{31} \mathrm{P} \mathrm{NMR}\left(\mathrm{CDCl}_{3}, 81 \mathrm{MHz}\right): \delta=36.1\left({ }^{1} J_{\mathrm{Pt}, \mathrm{P}}=2864 \mathrm{~Hz}\right)$. MALDI-TOF-MS: $m / z=4557.74$ (calcd. for $\mathbf{M}^{+}:$4557.11), 4478.12 (calcd. for $\left[\mathrm{M}^{+}-\mathrm{Br}\right]$ : 4477.20), 4315.55 (calcd. for [M+-3 Br]: 4317.38). Anal. calcd for $\mathrm{C}_{198} \mathrm{H}_{156} \mathrm{Br}_{6} \mathrm{P}_{12} \mathrm{Pt}_{12}$ : C 52.19, H 3.45, P 8.11; found: C 52.06, H 3.54, P 8.11.

\section{Synthesis of $5 e$}

A solution of hexakis $(\mathrm{PCHP}) 7(0.21 \mathrm{~g}, 70.6 \mu \mathrm{mol})$ and $\left[\mathrm{RuCl}(\mathrm{NCN})\left(\mathrm{PPh}_{3}\right)\right] \quad \mathbf{1 b}(0.25 \mathrm{~g}, \quad 0.42 \mathrm{mmol})$ in benzene $(40 \mathrm{~mL})$ was heated to reflux for $20 \mathrm{~h}$. Upon heating, a slow color change from dark purple to dark green was observed. The reaction mixture was allowed to cool to room temperature, filtered and the filtrate was evaporated to dryness. The resulting dark green solid was dissolved in degassed $\mathrm{CH}_{2} \mathrm{Cl}_{2}$ $(20 \mathrm{~mL})$ and the product was precipitated from this solution by slow diffusion of pentane. This procedure was repeated twice, affording a dark-green solid. Yield: $0.30 \mathrm{~g}$ (79\%). ${ }^{1} \mathrm{H}$ NMR $\left(\mathrm{CD}_{2} \mathrm{Cl}_{2}, 200 \mathrm{MHz}\right): \delta=8.1-6.4\left(\right.$ br m, $\left.222 \mathrm{H}, \mathrm{C}_{\text {aryl }}-\mathrm{H}\right), 3.67$ (br, $\left.12 \mathrm{H}, \mathrm{ArCH}_{2} \mathrm{P}\right), 3.19$ (br, 12H, $\left.\mathrm{ArCH}_{2} \mathrm{P}\right) ;{ }^{13} \mathrm{C} \mathrm{NMR}\left(\mathrm{CD}_{2} \mathrm{Cl}_{2}\right.$, $75 \mathrm{MHz}): \delta=165$ - $114\left(C_{\text {aryl }}\right), 43.3\left(\right.$ br, $\left.\mathrm{CH}_{2} \mathrm{P}\right) ;{ }^{31} \mathrm{P} \mathrm{NMR}$ $\left(\mathrm{CD}_{2} \mathrm{Cl}_{2}, 81 \mathrm{MHz}\right): \delta=80.8\left(\mathrm{~m}, \mathrm{PPh}_{3}\right), 40.7$ (app. m).

\section{Synthesis of 8}

A solution of $\mathbf{5 e}(0.30 \mathrm{~g}, 56.6 \mu \mathrm{mol})$ and $2,2^{\prime}: 6^{\prime}, 2^{\prime \prime}$-terpyridine ( $79 \mathrm{mg}, 0.34 \mathrm{mmol})$ in $\mathrm{MeOH}(15 \mathrm{~mL})$ was heated to reflux for $2 \mathrm{~d}$. In this period, a color change from dark green to brown red was observed. After cooling the mixture to room temperature, THF (15 mL) was added, affording a brown red precipitate. This precipitate was collected, washed with THF $(2 \times 10 \mathrm{~mL})$ and dried under vacuum, affording $8 \mathbf{a}$ as a brown red powder. Yield: $0.31 \mathrm{~g}(97 \%)$.

In order to replace the chloride counterion for a tetraphenylborate anion, 8a $(20 \mathrm{mg}, 3.6 \mu \mathrm{mol})$ was suspended in dry acetone $(2 \mathrm{~mL})$ and a solution of sodium tetraphenylborate $(7.4 \mathrm{mg}, 21.6 \mu \mathrm{mol})$ in dry acetone $(0.5 \mathrm{~mL})$ was added. Immediately, a clear solution was obtained and this mixture was stirred at room temperature for $2 \mathrm{~h}$. All volatiles were evaporated, the residue was extracted with $\mathrm{CH}_{2} \mathrm{Cl}_{2}(2 \mathrm{~mL})$ and slow addition of pentane to the $\mathrm{CH}_{2} \mathrm{Cl}_{2}$ solution resulted in the precipitation of a brown solid. This precipitate was collected 
and dried under vacuum, to give [hexakis(PCP-Ru-terpy) $]\left(\mathrm{BPh}_{4}\right)_{6}(\mathbf{8 b})$ as a brown solid. Yield: $22 \mathrm{mg}(90 \%)$.

8a: ${ }^{1} \mathrm{H}$ NMR (DMSO- $d_{6}, 300 \mathrm{MHz}$ ): $\delta=9.2-6.0$ (br $\mathrm{m}$, $198 \mathrm{H}, \mathrm{ArH}$ ), 3.52-4.40 (br m, 24H, $\mathrm{ArCH}_{2} \mathrm{P}$ ); ${ }^{13} \mathrm{C} \mathrm{NMR}$ (DMSO- $d_{6}, 75 \mathrm{MHz}$ ): $\delta=158-156,154-152,146-144,139-$ 126, 125 - 122 (all br, $\mathrm{ArC}$ ), $44.9\left(\mathrm{CH}_{2} \mathrm{P}\right) ;{ }^{31} \mathrm{P}$ NMR (DMSO- $d_{6}$, $81 \mathrm{MHz}): \delta=45.9\left(\mathrm{CH}_{2} P\right)$. Anal. calcd for $\mathrm{C}_{288} \mathrm{H}_{222} \mathrm{Cl}_{6^{-}}$ $\mathrm{N}_{18} \mathrm{P}_{12} \mathrm{Ru}_{6} \cdot\left(\mathrm{H}_{2} \mathrm{O}\right)_{24}: \mathrm{C}$ 62.23, $\mathrm{H}$ 4.90. $\mathrm{N}$ 4.54, P 6.69; found: $\mathrm{C}$ $62.84, \mathrm{H} 4.56, \mathrm{~N} 4.45, \mathrm{P} 6.79$.

8b: ${ }^{1} \mathrm{H}$ NMR $\left(\mathrm{CD}_{2} \mathrm{Cl}_{2}, 300 \mathrm{MHz}\right): \delta=8.2-6.0$ (br m, $318 \mathrm{H}$, $\operatorname{Ar} H$ ), 4.3-2.8 (br m, 24H, $\left.A r C H_{2} \mathrm{P}\right) ;{ }^{31} \mathrm{P} \mathrm{NMR}\left(\mathrm{CD}_{2} \mathrm{Cl}_{2}\right.$, $81 \mathrm{MHz}): \delta=46.6\left(\right.$ br s, $\left.\mathrm{CH}_{2} P\right)$.

\section{General Procedure for the Catalytic Hydrogen Transfer Reaction}

Complex 5e $\quad(17.7 \mathrm{mg}, \quad 3.3 \mu \mathrm{mol}=20 \mu \mathrm{mol} \quad[\mathrm{Ru}])$ or $\left[\mathrm{RuCl}(\mathrm{PCP})\left(\mathrm{PPh}_{3}\right)\right]$ 3b $(17.4 \mathrm{mg}, 20 \mu \mathrm{mol})$ was mixed with potassium hydroxide $(22 \mathrm{mg}, 0.4 \mathrm{mmol})$ in $i$-PrOH $(10 \mathrm{~mL})$ and the resulting mixture was heated to reflux for $1 \mathrm{~h}$, resulting in a brown suspension. Subsequently, a solution of the appropriate ketone $(20 \mathrm{mmol})$ in $i$-PrOH $(20 \mathrm{~mL})$ was added and the resulting solution was heated to reflux for several hours. The reaction was monitored by GC analysis with either $n$-decane (for cyclohexanone and acetophenone) or $n$-pentadecane (for benzophenone) as internal standard.

\section{Acknowledgements}

This work was supported by the Council for Chemical Sciences of the Netherlands Organization for Scientific Research (CW/ NWO).

\section{References and Notes}

[1] a) F. Gorla, A. Togni, L. M. Venanzi, A. Albinati, F. Lianza, Organometallics 1994, 13, 1607; b) J. M. Longmire, X. Zhang, M. Shang, Organometallics 1998, 17, 4374 .

[2] a) G. Zhu, M. Terry, X. Zhang, Tetrahedron Lett. 1996, 37, 4475; b) J. M. Longmire, X. Zhang, Tetrahedron Lett. 1997, 38, 1725 .

[3] a) M. Gupta, C. Hagen, R. J. Flesher, W. C. Kaska, C. M. Jensen, Chem. Commun. 1996, 2083; b) M. Gupta, W. C. Kaska, C. M. Jensen, Chem. Commun. 1997, 461; c) M. Gupta, C. Hagen. W. C. Kaska, R. E. Cramer, C. M. Jensen, J. Am. Chem. Soc. 1997, 119, 840; d) C. M. Jensen, Chem. Commun. 1999, 2443.

[4] M. Ohff, A. Ohff, M. E. van der Boom, D. Milstein, J. Am. Chem. Soc. 1997, 119, 11687.

[5] a) P. Dani, T. Karlen, R. A. Gossage, S. Gladiali, G. van Koten, Angew. Chem. Int. Ed. 2000, 39, 743; b) P. Dani, T. Karlen, R. A. Gossage, W. J. J. Smeets, A. L. Spek, G. van Koten, J. Am. Chem. Soc. 1997, 119, 11317.

[6] See ref. ${ }^{[1 a]}$ and: a) S. D. Perera, B. L. Shaw, J. Chem. Soc. Dalton Trans. 1995, 3861; b) C. J. Moulton, B. L. Shaw, J. Chem. Soc. Dalton Trans. 1976, 1020; c) S. Nemeh, C. M.
Jensen, E. Binamira-Soriaga, W. C. Kaska, Organometallics 1983, 2, 1442; d) M. E. van der Boom, S.-Y. Liou, Y. Ben-David, M. Gozin, D. Milstein, J. Am. Chem. Soc. 1998, 120, 13415; e) T. Karlen, P. Dani. D. M. Grove, P. Steenwinkel, G. van Koten, Organometallics 1996, 15, 5687.

[7] See ref. ${ }^{[5]}$ and: a) P. Dani, M. Albrecht, G. P. M. van Klink, G. van Koten, Organometallics 2000, 19, 4468; b) M. Albrecht, P. Dani, M. Lutz, A. L. Spek, G. van Koten, J. Am. Chem. Soc. 2000, 122, 11833.

[8] a) H. P. Dijkstra, P. Steenwinkel, D. M. Grove, M. Lutz, A. L. Spek, G. van Koten, Angew. Chem. Int. Ed. 1999, 38, 2186; b) H. P. Dijkstra, M. D. Meijer, J. Patel, R. Kreiter, G. P. M. van Klink, M. Lutz, A. L. Spek, A. J. Canty, G. van Koten, Organometallics 2001, 20, 3159; c) H. P. Dijkstra, C. A. Kruithof, N. Ronde, R. van de Coevering, D. J. Ramón, D. Vogt, G. P. M. van Klink, G. van Koten, J. Org. Chem., in press, manuscript available on the world wide web: http://pubs3.acs.org/acs/journals; d) H. P. Dijkstra, N. Ronde, G. P. M. van Klink, D. Vogt, G. van Koten, submitted; e) H. P. Dijkstra, M. Q. Slagt, A. McDonald, C. A. Kruithof, R. Kreiter, A. M. Mills, M. Lutz, A. L. Spek, G. P. M. van Klink, G. van Koten, Eur. J. Inorg. Chem., aceepted.

[9] For an overview on homogeneous catalyst recycling using ultra- and nanofiltration membranes, see: H. P. Dijkstra, G. P. M. van Klink, G. van Koten, Acc. Chem. Res. 2002, 35, 798.

[10] a) H. P. Dijkstra, A. Chuchuryukin, B. M. J. M. Suijkerbuijk, G. P. M. van Klink, A. M. Mills, A. L. Spek, G. van Koten, Adv. Synth. Catal. 2002, 344, 771; b) A. Chuchuryukin, H. P. Dijkstra, G. P. M. van Klink, R. J. M. Klein Gebbink, G. van Koten, Angew. Chem., accepted.

[11] H. P. Dijkstra, M. Albrecht, G. van Koten, Chem. Commun. 2002, 126.

[12] a) F. Gorla, L. M. Venanzi, A. Albinati, Organometallics 1994, 13, 43; b) M. A. Bennett, H. Jin, A. C. Willis, J. Organomet. Chem. 1993, 451, 249; c) M. E. van der Boom, H.-B. Kraatz, L. Hassner, Y. Ben-David, D. Milstein, Organometallics 1999, 18, 3873.

[13] D. Huang, W. E. Streib, J. C. Bollinger, K. G. Caulton, R. F. Winter, T. Scheiring, J. Am. Chem. Soc. 1999, 121, 8087.

[14] a) D. M. Grove, G. van Koten, J. N. Louwen, J. G. Noltes, A. L. Spek, H. J. C. J. Ubbels, J. Am. Chem. Soc. 1982, 104, 6609; b) A. W. Kleij, H. Kleijn, J. T. B. H. Jastrzebski, W. J. J. Smeets, A. L. Spek, G. van Koten, Organometallics 1999, 18, 268; c) A. W. Kleij, R. A. Gossage, R. J. M. Klein Gebbink, N. Brinkmann, E. J. Reyerse, U. Kragl, M. Lutz, A. L. Spek, G. van Koten, J. Am. Chem. Soc. 2000, 122, 12112.

[15] $\mathrm{BrC}_{6} \mathrm{H}_{3}\left(\mathrm{CH}_{2} \mathrm{PMe}_{2}\right)_{2}$-2,6 was lithiated with $n$-BuLi (bromo-lithium exchange) and transmetalated with $\mathrm{MgX}_{2}$ to give a PCP-magnesium complex: A. Pape, M. Lutz, G. Müller, Angew. Chem. Int. Ed. 1994, 33, 2281.

[16] P. Steenwinkel, S. Kolmschot, R. A. Gossage, P. Dani, N. Veldman, A. L. Spek, G. van Koten, Eur. J. Inorg. Chem. 1998, 477. 
[17] The lower activity per ruthenium center of $\mathbf{5 e}$ as compared to $\mathbf{3 b}$ results most likely from the fact that after addition of the cyclohexanone-solution, 5e solubilizes slower in the reaction mixture. In case of a fast catalytic reaction, i. e., reduction of cyclohexanone, this has a more significant effect on the TOF of $\mathbf{5 e}$ as compared to $\mathbf{3 b}$, leading to a decreased TOF per ruthenium center for $\mathbf{5 e}$.
[18] a) J.-P. Sutter, S. L. James, P. Steenwinkel, D. M. Grove, N. Veldman, A. L. Spek, G. van Koten, Organometallics 1996, 15, 941; b) P. Steenwinkel, S. L. James, D. M. Grove, N. Veldman, A. L. Spek, G. van Koten, Chem. Eur. J. 1996, 2, 1440. 